\title{
Longevity Tests of Rh/Al-Ce-Zr Catalyst for Auto-thermal Reforming of Diesel Oil
}

\author{
Won Young Choi, Yeon Baek Seong, Tae Hoon Lee, Chang Jun Park, Jin Wook Lee, Min Jung Kim, No- \\ Kuk Park, Tae Jin Lee* \\ School of chemical engineering Yeungnam University \\ 280 Daehak-Ro, Gyeongsan, Republic of Korea \\ cwy1990@naver.com; yeonbaek88@naver.com; 1th0830@naver.com; pcj0508@naver.com; 0327007@naver.com;
} mj0516kim@naver.com; nokukpark@gmail.com; tjlee@ynu.ac.kr

\section{Extended Abstract}

Recently, energy shortages are appearing constantly. Therefore, the research on alternative energy has demanded [12]. In this study, the catalytic activity of Rh-based supported catalysts was investigated for the auto-thermal reforming of diesel oil. The auto-thermal reforming of diesel oil occur the chemical reaction of steam, oxygen and the vaporized diesel gas, and it was performed at high temperature condition above at $800{ }^{\circ} \mathrm{C}$. Therefore, the catalytic activity can decrease by the sintering and the carbon coking. However, auto-thermal reforming has been considered as the appropriate method for diesel reforming, because auto-thermal reforming has showed less coke formation than other reforming method [2-5]. In this study, rhodium was used as the main active material for the production of hydrogen and the catalytic promoter was used alumina, zirconia, and ceria. Zirconia and ceria has been used as the catalytic promoter due to its high thermal stability and carbon coking resistibility. The Al-Ce-Zr based catalytic support material coated over metal foam plate was formed to the morphology of nano-structure. It was confirmed by XRD analysis that cerium and zirconium components in $\mathrm{Al}-\mathrm{Ce}-\mathrm{Zr}$ based catalytic support material was synthesized to $\mathrm{CeZrO}_{2}$ crystal structure. It was concluded that $\mathrm{CeZrO}_{2}$ prevents carbon deposition on catalyst active site due to their high lattice oxygen mobility. Carbon deposition is one of catalytic deactivation in hydrocarbons reforming reaction. The yield of hydrogen by diesel auto-thermal reforming increased with increasing reaction temperature, and was obtained 5, 15 and $43 \%$ at 600,700 and $800{ }^{\circ} \mathrm{C}$, respectively. The fuel conversions at same conditions were 20,85 and $100 \%$. The high hydrogen yield was obtained at 2.5 of steam/carbon ratio when reforming reaction was carried out at 800 . The optimum condition of oxygen/carbon was also confirmed to 0.25 . In this study, long-term activity test of Rh/Al$\mathrm{Ce}-\mathrm{Zr}$ based catalyst was carried out under the optimum auto-thermal reforming condition. The composition of hydrogen and carbon monoxide in dry product gas was maintained to approximately $45 \%$ and $11 \%$ during $500 \mathrm{~h}$, respectively. The theoretical composition of syn-gas, which is calculated by material balance under same condition, was $56 \%$. Therefore, it was concluded that the catalytic activity of $\mathrm{Rh} / \mathrm{Al}-\mathrm{Ce}-\mathrm{Zr}$ based catalysts is very excellent on diesel auto-thermal reforming. The carbon content on the surface of catalysts after 100, 200, 300, 400and $500 \mathrm{~h}$ reactions was investigated by EDX analysis and the carbon deposition was not observed. It was also confirmed by TEM analysis that the crystal size of catalytic support materials increased with increasing reaction time. It was concluded that the change of crystal size is occurred by the sintering of alumina and the crystallization of $\mathrm{CeZrO}_{2}$ at high temperature condition. However, catalytic deactivation by the change of crystal structure was not observed for $500 \mathrm{~h}$. It was expected that the crystallization of $\mathrm{CeZrO}_{2}$ prevents the deactivation by carbon deposition due to carbon oxidation of lattice oxygen in $\mathrm{CeZrO}_{2}$.

\section{References.}

[1] S. H. Lee, M. S. Bae, J. M. Bae, and S. P. Katikaneni, Int. J. Hydrogen Energy, vol. 40, pp. 3207-3216, 2015.

[2] D. Shekawat, D. Applegate, D. Miller L, H. K. Liao, and S. Ahmed, Int. J. Hydrogen Energy, vol. 19, pp. 184-254, 2006.

[3] J. T. Farrell, N. P. Cernansky, F. L. Dryer, C. K. Law, D. G. Friend, and C. A. Hergart, SAE. Tech. Pap., 2007-01-0201, 2007.

[4] S. Yoon, I. Kang, and J. M. Bae, Int. J. Hydrogen Energy, vol. 33, pp. 4780-4788, 2008.

[5] S. Yoon and J. M. Bae, Catal. Today, vol. 156, pp. 49-57, 2015. 